\title{
PROGRAM PEMBANGUNAN MASYARAKAT PULAU
}

\author{
Rodi Wahyudidan Larbiel Hadi \\ Fekonsos UIN Sultan Syarif Kasim Riau Pekanbaru
}

\begin{abstract}
Community development in border areas and islands is one of the main focuses of development by the central government. Regional development is not only in the capital of the province but also must pay attention to the condition of the community in the island region. The purpose of this study is to examine what type of development program is most needed by the community in the Meranti Archipelago Regency which consists of three large islands and is directly bordered by the Melaka Strait. Study data were collected using a questionnaire of 1,015 respondents spread across 9 districts. Data were analyzed by descriptive test using SPSS Version 20. The results showed that the most needed development programs in the Meranti Islands District were health service quality improvement $($ mean $=1,996)$, improved education facilities and quality (mean $=1,995)$, market $/$ basic food services cheap $($ mean $=1,992)$ and an increase in the price of plantation products, sago, rubber and copra $($ mean $=1.990)$. The type of development program that will be developed in the community is not only based on project benefits for certain parties but the development program that is needed by the community as an effort to improve their quality of life.
\end{abstract}

\begin{abstract}
Abstrak: Pembangunan masyarakat di kawasan perbatasan dan pulau menjadi salah satu fokus utama pembangunan oleh pemerintah pusat. Pembangunan daerah tidak hanya di kawasan ibu kota provinsi tetapi juga harus memperhatikan keadaan masyarakat di kawasan pulau. Tujuan kajian ini adalah meneliti apa jenis program pembangunan yang paling dibutuhkan oleh masyarakat di Kabupaten kepulauan Meranti yang terdiri dari tiga pulau besar dan berbatas langsung dengan Selat Melaka. Data kajian dikumpulkan dengan menggunakan angket sebanyak 1.015 responden yang tersebar di 9 kecamatan. Data dianalisis dengan uji deskriptif menggunakan SPSS Versi 20. Hasil penelitian menunjukkan bahwa program pembangunan yang paling diperlukan masyarakat di Kabupaten Kepulauan Meranti adalah peningkatan kualitas layanan kesehatan (mean=1,996), peningkatan sarana dan kualitas pendidikan (mean=1,995), operasi pasar/sembako murah (mean $=1,992)$ dan peningkatan harga hasil perkebunan;sagu, karet dan kopra $($ mean=1,990). Jenis program pembangunan yang akan dibangunkan di masyarakat bukan hanya berdasarkan keuntungan proyek bagi pihak tertentu tetapi program pembangunan yang sangat diperlukan oleh masyarakat sebagai usaha peningkatan kualitas hidup mereka.
\end{abstract}

Kata kunci: program pembangunan, partisipasi masyarakat, pemberdayaan masyarakat pulau

\section{PENDAHULUAN}

Pembangunan merupakan proses perubahan secara bertahap menuju kearah yang lebih baik dalam rangka mewujudkan masyarakat sejahtera lahir dan batin di kehidupan dunia yang sementara dan di kehidupan akhirat yang selama-lamanya. Isu pembangunan yang sampai hari ini masih belum dapat diselesaikan adalah keadilan dan pemerataan pembangunan. Para ilmuan pula menilai pembangunan sesuai dengan bidang masing-masing. Pakar ekonomi pembangunan menekankan aspek pertumbuhan ekonomi seperti mana yang ditulis Ong Puay Liu (2007) menyatakan bahwa pembangunan erat kaitannya dengan pertumbuhan ekonomi sehingga menjadi dasar dalam mengukur kemajuan pembangunan di negara sedang membangun. Ideologi pembangunan ini menganggap negara dan manusia yang menginginkan pembangunan didorong oleh kepentingan diri yang rasional yaitu memaksimalkan keuntungan dan pemilikan kekayaan material.

Fokus pembangunan pada aspek ekonomi telah dikritik oleh para pakar yang bidangnya bukan ekonomi bahwa pembangunan tidak seharusnya menitikberatkan pertumbuhan ekonomi semata-mata tetapi harus menyeluruh dan seimbang dengan kesejahteraan dan peningkatan martabat manusia sebagai tujuannya. Secara filosofi, pembangunan membayangkan kemajuan yang mengimplikasi evolusi ke arah yang menguntungkan pada waktu dan tempat tertentu (Wallman, 1997). Dalam bidang ekologi manusia, pembangunan merupakan satu pendekatan integrasi yang sistemik, saling berkait dan multidimensi yang merangkumi perubahan masyarakat, sikap dan infrastruktur (Miller, et al., 1989). 
Ilmuan dalam bidang sosial pula mendefenisikan pembangunan sebagai proses perubahan sosial yang bersifat lebih menyeluruh dan terbagi kepada dua kategori utama, yaitu pertama pembangunan yang direncanakan dan kedua, pembangunan yang tidak direncanakan (Shamsul, 1990).

Setelah penulis menelusuri beberapa hasil kajian terdahulu, masih sangat sedikit kajian tentang pembangunan masyarakat pulau terluar dan tertinggal. Padahal kalau kita mau jujur masih banyak wilayah di Indonesia termasuk Provinsi Riau yang perlu menjadi perhatian peneliti yang dikaji. Tatan Sukwika (2018) telah melakukan kajian megenai peran pembangunan infrastruktur terhadap ketimpangan ekonomi antar wilayah di Indonesia. Hasil kajian menunjukkan bahwa adanya kesenjangan ekonomi yang cukup tinggi antar provinsi di Indonesia selama periode 20112015. Tingginya kesenjangan tersebut seringkali diasosiasikan dengan kesenjangan infrastruktur yang terjadi antar provinsi. Temuan ini merupakan pesan kuat bagi pemerintah untuk perlu mengakselerasi program pemerataan pembangunan secara proposional terutama di wilayah yang dianggap masih tertinggal sehingga proses pembangunan infrastruktur tidak jauh tertinggal dengan wilayah yang sudah maju.

Berdasarkan hasil kajian Putra dan Dilham (2017) di Kelurahan Bukit Timah menjelaskan bahwa potensi yang dimiliki Bukit Timah baik di bidang sosial maupun ekonomi ternyata masih belum bisa mengatasi permasalahan yang dialami Bukit Timah. Untuk masalah sosial sendiri, Bukit Timah masih me-ngalami lingkungan yang terjerat narkoba. Terdapat beberapa wilayah masih mengalami kekurangan sarana rumah ibadah, sulitnya men-dapatkan air bersih dan masih terdapat wilayah yang mengalami musibah banjir dan kebakaran lahan. Dibagian kesehatan masih ada wilayah yang terserang wabah penyakit rabies, DBD, Malaria, Cikungunya dan Flu Burung. Sarana infrastruktur juga menjadi masalah yang dialami Bukit Timah seperti transportasi untuk kesekolah tidak ada karena tidak ada angkutan umum, infrastruktur jalan yang belum tersemenisasi. Berbagai harapan masyarakat Bukit Timah mengharapkan bantuan berupa adanya pembangunan jalan yang rusak, pemberian sumur bor dan lapangan pekerjaan, adanya bantuan berupa pupuk dan perluasan lahan serta bantuan biogas dan pupuk kompos.

Firdaus, Fauzi dan Assyifa (2018) pula telah melakukan penelitian di Desa Mandiangin Barat menyatakan bahwa masyarakat Desa Mandiangin Barat merupakan masyarakat perdesaan yang cenderung masih memanfaatkan sumber daya alam di sekitar mereka untuk dikelola dalam bidang pertanian (sawah) dan perkebunan (kebun karet dan buah), sehingga dari pekerjaan seperti ini masyarakat Mandiangin kebanyakan memiliki penghasilan perbulan rata-rata antara Rp.500. 000-Rp.1000.000. Etnis yang mendiami lokasi penelitian sebagian besar suku banjar dengan lama bermukim di atas 25 tahun yang menandakan mereka sebagai penduduk asli karena lahir di desa ini. Desa Mandiangin Barat memiliki lembaga-lembaga desa yang memiliki tugas dalam pembangunan desa. Lembaga yang dimiliki Desa Mandiangin Barat hampir sama dengan lembaga-lembaga yang ada di desa lain namun fasilitas pembangunan sangat minim seperti satu kantor desa digunakan juga sebagai kantor lembaga lainnya yang ada di desa.

Selanjutnya Sari dan Tahir (2018) telah melakukan kajian di Desa Bongki Lengkese Kecamatan Sinjai Timur Kabupaten Sinjai, menyatakan bahwa kolaborasi aktor pembangunan di Desa Bongki Lengkete menunjukan ketahanan sosial berupa gotong royong yang masih terjaga dengan baik oleh masyarakat, meskipun belum menunjukan hasil pada ekonomi khususnya mandiri pangan bagi sebagian masyarakat, begitu pula dalam hal energi listrik. Meskipun demikian selama beberapa tahun terakhir telah menunjukan upaya para aktor pembangunan dalam mengambil peran selaku penggerak ekonomi masyarakat setempat. Hal ini dibuktikan dengan pengembangan kelompok usaha bersama (KUB) berupa kambing, KUB Melati, penggemukan sapi dan pandai besi.

Pendekatan pembangunan yang terlalu menekankan pertumbuhan ekonomi telah mengabaikan ketidaksamaan yang muncul antara kawasan kota dan desa. Achda (2004) menjelaskan bahwa, strategi pembangunan nasional 
cenderung diarahkan kepada pembangunan kawasan kota yang dilaksanakan secara terencana dan terpadu. Sebaliknya, pembangunan kawasan terluar dan terpinggir seringkali diserahkan kepada masyarakat itu sendiri untuk mengusahakannya. Akibatnya terjadi ketidakseimbangan dalam pengelolaan sumber keuangan, pembangunan infrastruktur, pendidikan, kesehatan dan tingkat pendapatan. Menurut Rahamah dan Hair (2005), kejayaan membangunkan komunitas desa secara holistik menjadi idaman setiap perencanaan pembangunan, khususnya di negara sedang membangun. Gagasan membangunkan komunitas desa bukan saja tertumpu kepada membangunkan infrastruktur semata-mata, malah lebih penting adalah usaha pertumbuhan ekonomi desa seiring dengan pembangunan sosial komunitas desa. Komunitas desa terus dibangunkan bukan saja untuk mengekang melebarnya jurang pembangunan social-ekonomi desa-kota, malah untuk mengurangkan ketidaksamaan pendapatan antara golongan miskin dan kaya.

Berkurangnya kesenjangan merupakan salah satu dari 17 tujuan Pembangunan Berkelanjutan(SDGs) 2015-2030 yang disepakati dan berlaku bagi seluruh bangsa tanpa terkecuali. SDGs berisi 17 tujuan yaitu tanpa kemiskinan, tanpa kelaparan, kehidupan sehat dan sejahtera, pendidikan berkualitas, kesetaraan gender, air bersih dan sanitasi layak, energi bersih dan terjangkau, pekerjaan layak dan pertumbuhan ekonomi, industri, inovasi dan infrastruktur, berkurangnya kesenjangan, kota dan komunitas berkelanjutan, konsumsi dan produksi bertanggung jawab, aksi terhadap perubahan iklim, ekosistem laut, ekosistem darat, perdamaian, keadilan dan kelembagaan yang tangguh dan kemitraan untuk mencapai tujuan.

Berdasarkan beberapa hasil kajian terdahulu dan pendapat para pakar pembangunan, maka peneliti tertarik untuk melakukan kajian di salah satu kabupaten di Provinsi Riau yang terdiri dari tiga pulau besar dan berbatas langsung dengan Selat Melaka, yaitu Kabupaten Kepulauan Meranti. Apa jenis program pembangunan yang sangat diperlukan oleh masyarakat Kepulauan Meranti merupakan fokus utama artikel ini.

\section{METODE}

Metode yang digunakan dalam penelitian ini adalah kuantitatif. Data kajian dikumpulkan dengan menggunakan angket sebanyak 1.015 responden yang tersebar di 9 kecamatan di Kabupaten Kepulauan Meranti. Teknik menentukan jumlah sampel penelitian menggunakan pendapat Tabel Isaac \& Michael (1980) bahwa apabila populasi kurang dari 200.000 orang, maka jumlah sampel minimum adalah 661 orang. Jumlah penduduk Kabupaten Kepulauan Meranti sebanyak 183.297 (BPS Kabupaten Kepulauan Meranti, 2018). Terdapat 7 program pembangunan yang diperlukan masyarakat Meranti diukur dalam penelitian ini yaitu Bangun infrastruktur daerah, Naikkan harga sagu, karet dan kopra (Hasil Perkebunan), Tutup/Kurangi beroperasinya tempat maksiat, Operasi Pasar (Sembako Murah), Peningkatan kualitas layanan kesehatan, Peningkatan sarana dan kualitas pendidikan dan Bantuan pembangunan sarana rumah ibadah. Data dianalisis dengan uji deskriptif menggunakan SPSS Versi 20.

\section{HASIL DAN PEMBAHASAN}

Data menunjukkan demografi responden bahwa kebanyakan pekerjaan responden adalah petani $(20,9 \%)$, jenis kelamin laki-laki sebanyak 629 orang $(62,0 \%)$ dan perempuan sebanyak 386 orang $(38,0 \%)$. Mayoritas agama responden adalah Islam $(98,9 \%)$ berbanding Kristen Katolik yang hanya 5 orang $(0,5 \%)$ dan Kristen Protestan sebanyak 2 orang $(0,2 \%)$. Berdasarkan tingkat pendidikan, responden lulusan SLTA sebanyak 286 orang $(28,2 \%)$, lulusan SLTP sebanyak 161 orang $(15,9)$, lulusan SD/tidak Tamat SD sebanyak 485 orang $(47,8 \%)$ dan lulusan perguruan tinggi sebanyak 83 orang $(8,2 \%)$.

Tabel 1 di bawah menunjukkan bahwa program pembangunan yang paling diperlukan masyarakat di Kabupaten Kepulauan Meranti adalah peningkatan kualitas layanan kesehatan ( $m e a n=1,996$ ), peningkatan sarana dan kualitas pendidikan (mean=1,995), operasi pasar/sembako murah (mean=1,992) dan peningkatan harga hasil perkebunan; sagu, karet dan kopra ( mean $=1,990)$. Jenis program pembangunan 
yang akan dibangunkan di masyarakat bukan hanya berdasarkan keuntungan proyek bagi pihak tertentu tetapi program pembangunan yang sangat diperlukan oleh masyarakat sebagai usaha peningkatan kualitas hidup mereka.

Table 2. Uji Deskriptif Program Pemerintah yang Paling dibutuhkan Masyarakat Meranti

\begin{tabular}{lc}
\hline \multicolumn{1}{c}{$\begin{array}{c}\text { Uji Deskriptif Program Pemerintah yang Paling } \\
\text { dibutuhkan Masyarakat Meranti }\end{array}$} & Mean \\
\hline Bangun infrastruktur daerah & 1,988 \\
Naikkan harga sagu, karet dan kopra (Hasil Perkebunan) & 1,990 \\
Tutup/Kurangi beroperasinya tempat maksiat & 1,987 \\
Operasi Pasar (Sembako Murah) & 1,992 \\
Peningkatan kualitas layanan kesehatan & 1,996 \\
Peningkatan sarana dan kualitas pendidikan & 1,995 \\
Bantuan pembangunan sarana rumah ibadah & 1,990 \\
\hline
\end{tabular}

\section{Peningkatan Kualitas Layanan Kesehatan}

Kabupaten Kepulauan Meranti adalah kabupaten yang memiliki sembilan kecamatan didalamnya tiga kecamatan terletak di pulau tebing tinggi, 3 kecamatan di pulau rangsang dan tiga kecamatan terletak di pulau padang. Kecamatan Tasik Putri Puyu merupakan kecamatan terjauh yang berjarak kurang lebih $97 \mathrm{~km}$ dari ibukota Kabupaten. Kondisi geografis Kabupaten Kepulauan Meranti yang terdiri dari tiga pulau besar menyebabkan layanan kesehatan belum bisa memuaskan masyarakat. Apabila masyarakat yang memerlukan layanan kesehatan seperti cek kesehatan, konsultasi kehamilan, sakit biasa seperti demam, flu dan sebagainya tidaklah menjadi persoalan. Tetapi bayangkan apabila ada masyarakat yang perlu penanganan medis (emergency) yang tidak cukup oleh layanan puskesmas, maka pasien harus dibawa ke rumah sakit besar. Padahal jarak antar pula dengan menggunakan speedboad atau pompong memerlukan waktu tempuh yang cukup lama karena harus menyeberang pulau.

Layanan kesehatan yang berkualitas merupakan harapan seluruh masyarakat Meranti, maka pemerintah daerah harus melakukan program nyata yang dapat memberikan kepuasan pelayanan baik dari aspek sarana maupun kualitas tenaga medis. Rumah sakit/puskesmas terapung yang bisa mendatangi kawasan pulau kecil yang masih belum terdapat puskesmas adalah sangat mendesak agar masyarakat di pulau terpencil tetap mendapat layanan kesehatan. Selain itu, cara pengobatan tradisional (alami) tetap harus dilestarikan agar ketergantungan dengan dokter, perawat dan bidan dapat dikurangi.

\section{Peningkatan Sarana dan Kualitas Pendidikan}

Tiada cara yang paling cepat untuk mengubah diri, keluarga dan masyarakat kecuali melalui pendidikan. Masyarakat desa juga sudah memiliki kesedaran yang sama dalam meningkatkan kualiti sumber manusia melalui peningkatan ilmu dan kemahiran, yaitu pendidikan. Namun, permasalahan umum berlaku pada masyarakat miskin desa adalah tiada kemampuan untuk membiayai sekolah/kuliah anak akibat beban ekonomi yang cukup berat(Wahyudi, et.al. 2018). Masyarakat di Kabupaten Kepulauan Meranti harus siap bersaing dengan kawasan lain dari segi kualitas sumber daya manusia, pengembangan potensi daerah dan pembangunan infrastruktur. Sarana pendidikan seperti gedung belajar, buku ajar, perpustakaan termasuk juga kualitas guru dan kesejahteraan guru.

Sarana dan kualitas pendidikan yang dimaksud disini bukan hanya pendidikan formal (SD, SLTP dan SLTA) termasuk sarana dan kualitas pendidikan non formal (MDTA, Madrasah Tahfiz. Masyarakat Meranti merupakan masyarakat melayu yang masih kuat mengamalkan ajaran Islam dan adat resam Melayu. Sifat kurang peduli pemerintah daerah terhadap penyediaan sarana dan peningkatan kualitas pendidikan sama artinya membiarkan masyarakat hidup dalam keadaan bodoh. Masyarakat yang kurang ilmu akan mudah ditipu oleh pihak luar yang ingin menguasai asset dan potensi alam di Kabupaten Kepulauan Meranti. Jangka panjang keadaan ini sangat berbahaya dan bisa menyebabkan konflik sosial. Orang pendatang hidup kaya (karena memiliki ilmu dan keterampilan) sedangkan masyarakat tempatan hidup miskin karena kalah bersaing akibat tidak cukup ilmu dan keterampilan.

\section{Operasi Pasar/Sembako Murah}

Akibat murahnya harga jual karet, kelapa sawit dan sagu sebagai sumber utama petani di Kabupaten Kepulauan Meranti, maka tingkat daya beli masyarakat terhadap bahan kebutuhan 
pokok menjadi rendah. Hasil tangkapan nelayan pula juga tidak sebanyak tahun sebelumnya akibat musim gelombang tinggi di laut. Tingkat daya beli masyarakat berkurang sebagai akibat berkurangnya jumlah pendapatan, maka dapatan kajian ini menunjukkan bahwa masyarakat Meranti sangat menginginkan adanya operasi pasar/sembako murah sebagai salah satu pilihan agar tetap bisa membeli bahan kebutuhan pokok. Pemerintah daerah bersama seluruh perangkat Satuan Kerja Perangkat Daerah segera melakukan tindakan konkrit dalam mengatasi keluhan masyarakat. Jangan hanya ketika musim pimilihan kepala daerah, pemilihan anggota legislatif dan pemilihan presiden dan wakil presiden sibuk membagikan sembako murah agar dipilih masyarakat tetapi setelah selesai pilkada dan pemilu dan masyarakat dilupakan. Padahal masyarakat memerlukan bahan kebutuhan pokok bukan hanya pada musim pilkada dan pemilu saja. Bulog, Dinas Pasar dan pihak lain yang bisa diajak bekerjasama perlu dilibatkan agar setiap masyarakat dapat hidup dengan tenang dan berkecukupan.

\section{SIMPULAN}

Program pembangunan yang paling diperlukan masyarakat di Kabupaten Kepulauan Meranti adalah peningkatan kualitas layanan kesehatan, peningkatan sarana dan kualitas pendidikan, operasi pasar/sembako murah dan peningkatan harga hasil perkebunan;sagu, karet dan kopra. Pemerintah yang baik adalah pemerintah yang mampu menunaikan hajat rakyatnya sehingga ia dicintai dan dido'akan oleh rakyat. Sebaliknya pemerintah yang buruk adalah pemerintah yang sibuk dalam kemewahan sampai lupa bahwa masih banyak rakyatnya yang kelaparan, tidak makanan, tidak bisa menyekolahkan anak. Rakyat akan mendoakan keburukan terhadap pemerintah yang zolim kepada rakyat bahkan tidak jarang mereka melakukan pemberontakan akibat beratnya tekanan hidup yang mereka alami. Sifat rakyat yang terbaik adalah ikhtiar dengan sungguh-sungguh, jangan pemalas, ketika keadaan buruk dating jangan menyalahkan pemerintah tapi salahkan diri sendiri (bisa jadi keadaan buruk yang terjadi akibat amal buruk diri sendiri). Kehidupan dunia sangat sementara, sebenarnya inilah peluang yang sangat besar bagi pemerintah untuk beramal sholeh dengan cara berkhidmat, melayani masyarakat, mencukupi yang kekurangan, membantu yang lemah, sehingga wujudlah suasana masyarakat yang harmonis dan berkasih sayang buah dari sifat saling menunaikan hak satu sama lain. Rakyat tunaikan kewajiban terhadap pemerintah dan pemerintah pula menunaikan kewajiban terhadap rakyatnya.

\section{DAFTAR PUSTAKA}

M. Umar Maya Putra dan Ami Dilham. 2017. Pemetaan Sosial Ekonomi Masyarakat Kecamatan Dumai Timur (Studi Kasus: Kelurahan Bukit Timah). Jurnal Wira Ekonomi Mikrosil. Volume 7 Nomor 1. Hal. 1-8.

Miller, J. N. L. \& Vaughan, G. 1989. Development Education: An Integrative Approach. Journal Of Home Economic 81: 21-26.

Muhammad Fauzan Firdaus, Hamdani Fauzi dan Assyifa . 2018. Pemetaan Sosial (Social Mapping) Masyarakat Sekitar KHDTK UNLAM di Desa Mandiangin Barat. Jurnal Sylva Scientea. Vol. 01 No. 1. Hal. 92-103.

Noor Rahamah Abu Bakar, \& Abd Hair Awang. 2005.Pembangunan sosio-ekonomi komuniti desa di Daerah Kuala Selangor dan Kabupaten Tangerang. Bengkel penyelidikan bersama Malaysia-Indonesia: Perbandingan pembangunan komuniti pada 17-18 November 2005 di Sudut Wacana, ATMA, UKM Bangi.

Ong Puay Liu. 2007. Pedagogi Pembangunan, Ke Arah Dialog Bermakna Antara PenggubalDasardan SasaranPembangunan.

Kertas kerja yang dibentangkan dalam Persidangan Antarabangsa Fakulti Sains Sosial dan Kemanusiaan Kedua (ICOSH 07), anjuran Fakulti Sains Sosial dan Kemanusiaan, UKM Bangi pada 13-15 Marc 2007.

Riska Sari dan Nurbiah Tahir. 2018. Kolaborasi Aktor Pembangunan dalam Mewujudkan 
Desa Mandiri di Desa Bongki Lengkese Kecamatan Sinjai Timur Kabupaten Sinjai. Jurnal Ilmiah Ilmu Administrasi Publik, Volume 8 Nomor 2. Hal. 121-126.

Rodi Wahyudi, Mahendra Romus, Jalaluddin Abdul Malek, Rusdi, Muammar Alkadafi, \& Mashuri. 2018. Keperluan Masyarakat Miskin Desa dalam Program Pembangunan Desa di Kecamatan Kuantan Mudik, Provinsi Riau, Indonesia. Malaysian Journal of Society and Space, Volume 14, Nomor 2, Hal. 1-12.

Shamsul, A. B. 1990. Masyarakat Malaysia Yang Membangun. Kuala Lumpur: Dewan Bahasa dan Pustaka.
Tamam Achda. 2004. Mendahulukan yang tertinggal (2), laporan studi penjajakan kebutuhan program adopsi desa miskin di Jawa Barat. Jakarta, Penerbit Pusat Pemberdayaan Masyarakat Universitas Nasional.

Tatan Sukwika. 2018. Peran Pembangunan Infrastruktur Terhadap Ketimpangan Ekonomi Antar Wilayah di Indonesia. Jurnal Wilayah dan Lingkungan. Volume 6 Nomor 2. Hal. 115-130.

Wallman, S. 1997. Perceptions of Development. Cambridge: Cambridge University. 